\title{
ANIMAL RIGHTS: Broadening Our Perspective; Broadening Our Base
}

\section{DOUG MOSS}

The Animals' Agenda

Probably the very first revelation I had about animals, as a very young person (about age ten), was when I was driving in the car with my father and he ran over a squirrel. I was horrified first to know that such things happened at all, and doubly so because we had done it. I was quite shaken, looking back seeing
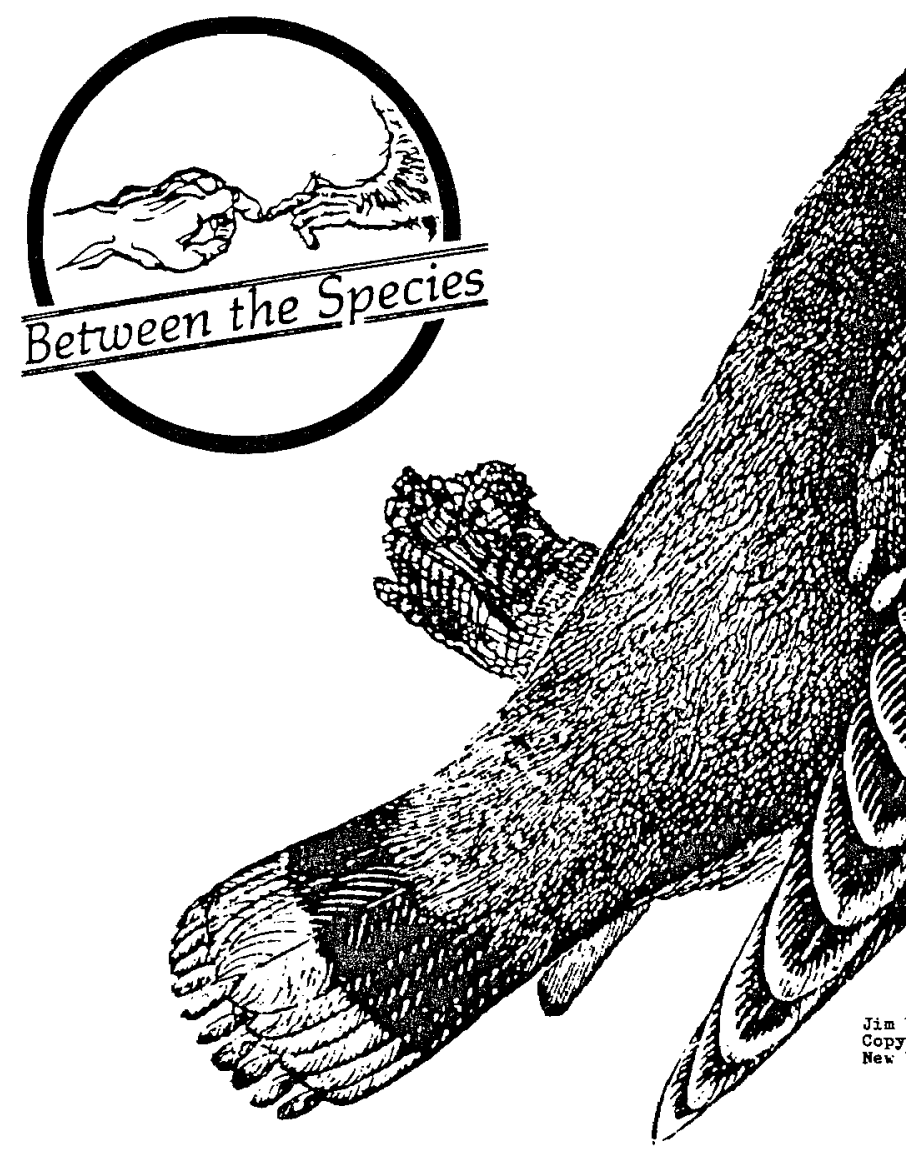

just the furry tail sticking up from the pavement with the body of the animal now glued to the surface. My dad later remarked that he thought it was good that I had those

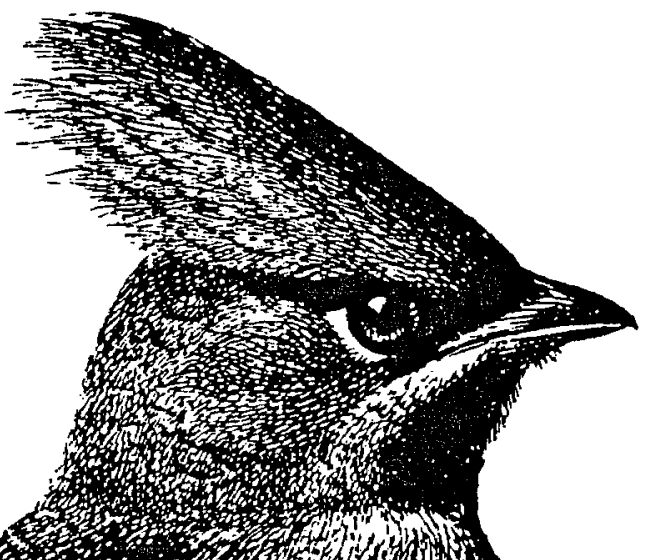


feelings for the hapless creature.

As an adult, my first introduction to the realitites of animal suffering came when I was living in New Haven, Connecticut and I was stopped at a traffic light by a fur store where a group of people were making a ruckus and handing out gory brochures. I took one that was offered to me through the window of my car and my heart literally sank. Here I was, 22 years old and l'd never consciously associated fur coats with dead animals! We all know the brochure---that glossy one with several folds with the white artic fox in the bloody snow. I consider that cold day in New Haven the day I began my personal "politicization" because it marked the beginning of an all-round new awakening for me, not just regarding animals, but with respect to many social issues I would later fill my head with.

Less than a week after running into the protesters at the New Haven fur store, while watching the news at home I chanced upon the clubbing of baby white harp seals in Newfoundland. Not really relating this to my experience a few days earlier downtown, I was nevertheless greatly angered by the news report. My first reaction was to call the TV station to yell at them for showing me this atrocity. I stopped midway through dialing, however, and realized that it was silly to be blaming the TV reporters for televising this. After all, it wasn't their fault. In fact, it was good that they were showing me this! Although I would not translate this, in part, into vegetarianism until a few years later, I was now beginning to think a great deal about our treaiment of animals.

A short time later I moved out of New Haven to another part of the state where, while grocery shopping one day, I ran into a middle-aged woman who was distributing literature and selling buttons, bumper-stickers and dolls to raise money for her local rescue group, PAWS. The burgeoning rebel in me automatically took to her and, before long, it was 1 who was standing in front of that and many other local supermarkets, talking (and often arguing) with people as they made their way, (sometimes dressed in furs, of course), in and out of the stores with their grocery carts. I moved a let of literature, bumper stickers and buttons for PAWS, (everything but the dolls---sheesh!), and would later meet a number of local 'animal people' and work with them on numerous local fundraising functions. I owe a lot to Tillie Motyl and Betty Long of PAWS for having gotten me into the trenches of local animal work. Whatever cynicism one might have about proverbial "little old ladies in tennis shoes", the reality is that these women , present in almost every community, have been the unsung backbone of this movement long before "animal rights", as we now know it, began to gain its new momentum in recent years.

It was through PAWS people that I soon came to know quite a large group of people in the progressive community in and around Newport, Connecticut, a town known more for its wealth (and celebrities like Paul Newman) than for any kind of liberal activity. .certainly no Madison, Wisconsin, in any case, but surprisingly rich in people involved (or at least marginally interested) in social change activities. It was here that I found my "family"; people whose lives were dominated by their passion for social change work; people who embraced many of the ideals that I was now beginning to care about. I quickly became quite active in opposing the reinstatement of the draft, in anti-nuclear work, and in a group called "Coalition for a Just Society" which eventually chose, as its main activity, working as the Connecticut chapter of the Citizen's Party which, in 1980, ran Barry Commoner and LaDonna Harris as its Presidential and Vice-Presidential candidates. I was ballotaccess coordinator for the Commoner effort in Southern Connecticut and succeeded, along with a team of others, in getting Commoner on the ballot for that fateful year which first elected Ronald Reagan and saw John Anderson as the spoiler for other candidates like Commoner who were championing progressive ideas. 
It was during this same period (1977) that some of us (the activist core of the local politically-interested community) founded a chapter of a prominent national animal organization. This was my first real introduction to the intra-movement "politics" that so many of us know only too well. I was amazed at the viciousness with which this organization's leaders regarded other groups in the movement, and at the extremes they would go to to compete for "top billing" in a shared event, or to publicly put down other animal groups. We gave the chapter our best but, having learned, as well, through our other political work how damaging all the rivalries and petty bickering can be to the effectiveness of any social change movement, we left, albeit rather abruptly and unpleasantly, to regroup and to try a new approach that might help overcome this sectarianism. Realizing, particularly from this experience, that part of the movement's development was going to require some internal work (at least rudimentary communicaton and cooperation between groups), we formed Animal Rights Network. Out of that grew what is now THE ANIMALS' AGENDA.

I'm very proud of ANIMALS' AGENDA and how it's evolved and managed to survive and remain relevant to a changing movement. As many people may know, The ANIMALS' AGENDA started out in late 1979 as two separate publications: a journal entitled simply "AGENDA", and a bi-monthly newsletter, The Animal Bights Network News. Both publications sought to provide the budding movement with a clearinghouse of information, ideas, and strategies,---a bulletin board for sorely-needed communication between many groups which seemed to be perenially caught up in a kind of xenophobia toward one another.

AGENDA was the more theoretical, philosophical, and intellectual of the two, publishing discussions about the problems with the movement (or the lack of a cohesive movement at the time) and about the traditional animal societies. It included frank dialog about intra-movement concerns, such as whether or not animal advocates should be vegetarian, and whether or not we should think of animal rights issues as related to other issues for social justice. Animal Rights Network News was more upbeat and far less esoteric, profiling new grassroots organizations, reviewing books, and providing national and international "network" news as inspiration for those anxious to break from the traditional "send-a-check-to-the-society-andthings-will-be-alright" mindset, and eager to work locally or nationally to effect stronger changes for animals.
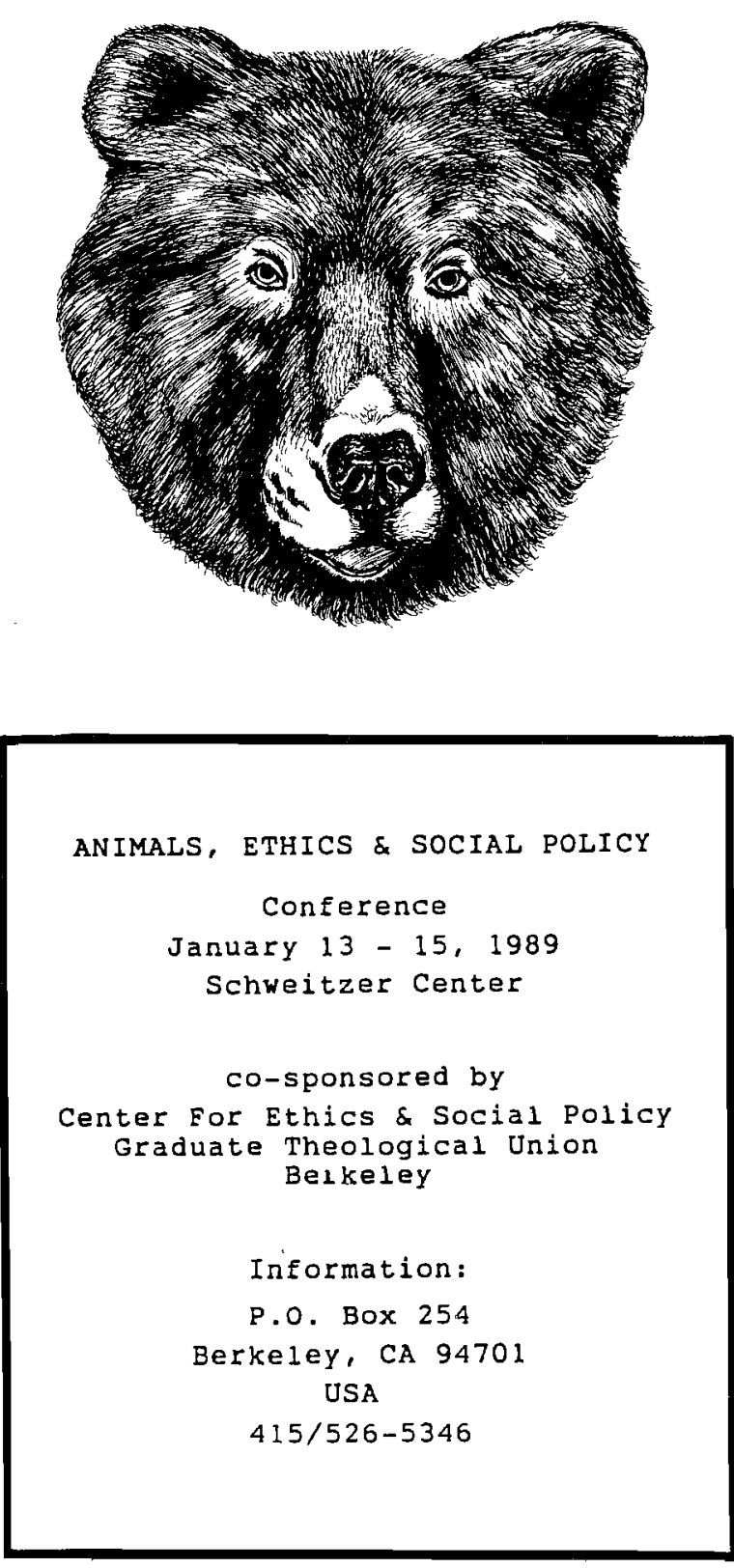
Though billed as a co-editor on the masthead from the beginning, my job encompassed everything from paste-up to keypunch to mailing house manager to direct mail coordinator to grantsman. AGENDA first occupied part of a 150 square foot basement office, sharing space with my small business forms company which donated the rent and, as time went on, many of the salaries and other expenses. Much of the work was done at home, though, and we (mostly Jim Mason and myself) labored hard and furiously to get out each issue. Bi-monthly mailing-and-pizza parties with a few of our local friends took care of getting the publications stapled together, labeled and bagged for the post office, and my car was nearly always full of papers, mail sacks and trays as I made the runs to and from the printer and the post office.

As the circulation of the two publications began to take off, and the respective audiences seemed to overlap almost entirely, we decided to combine them into one, and later re-named it The ANIMALS' AGENDA. Part of the reason for the name change was that we knew the magazine was starting to be seen by people other than just the "hard core" of the movement, and that the very least we should do is put "animals" in the title somewhere. In fact, I remember many times when l'd be talking with someone not already familiar with animal rights and they'd ask me what I did. I'd tell them I published an animal rights magazine and then l'd show them a copy of something called "agenda", often an issue with a rather weird-sounding cover title. I began to think that there was more potential to this little rag than just trying to talk to "movement people" with it, so I pushed for a more mainstream look, a slightly more popular-appealing editorial makeup, and more accessible overall tone. The skill in putting together an effective "alternative" publication is in how you package

radical ideas ("sugar-coat" them, if you will) so that the magazine will get picked up and read and taken seriously, by the media and other influential centers, as well as by the average person you're trying to win over. In 1986 we "went glossy," and set our sights on getting some newsstand and library circulation, evolving the magazine into more of an information source than a journal. The emphasis changed to one of enlightening general readers, with an eye towards drawing them into the movement.

Some activists lament AGENDA's evolution away from its in-house beginnings, but the magazine had to evolve because it became such a centralized entity (everyone sent us news and commentary from all over and treated us like the "animal media"). I feel that we did what we had to do, to rise to the occasion and to keep pace with the movement's momentum. Besides, if a movement is performing well, other publications should step in and fill the niches that are left behind. In fact, I think that has happened to a certain extent. Having a newsstand-quality magazine for animal rights, to me, means legitimizing this movement in the eyes of the public as well as the media's (we've concentrated on building our media list, too). We live in a time when "special interest" magazines are the rage, so the timing is right to get animal rights out there on the newsstand, a unique and very important part of today's "mass media".

I am genuinely excited about the future of this movement, though I do feel we have some serious problems to overcome. The movement has successfully put animal rights onto the debate table, but I think we still face an image problem related to the very "narrowness" of our perspectives, and this often leaves us on shaky ground. There is definitely a new ethic emerging in society that is demanding a reevaluation of our attitudes towards animals. Yet this new ethic is not limited to just animals, but is instead addressing our attitudes and behavior towards all of nature. Animals are, of course, a major part of this emerging ethic, the "gate" through which people must pass to comprehend the greater issues that will decide the future of all of nature, so we certainly need people to concentrate their efforts in this particular area. 
What I would take issue with is our problem of approach. Like it or not, the more effective activists in the years immediately ahead are going to be people who embrace the larger questions that face us, and who demonstrate the amplitude of this vision in the course of their actions, discussions (with media or whomever), and writings. Let me put it this way: Earlier in this essay I used the term "animal people," but in all honesty I hate that expression! In recent conversations with movement people about the controversy over whether or not Bob Dole should be supported as a presidential candidate, it was frequently suggested that "animal people" support Dole, or "animal people" not alienate Dole (through published criticism), because he's voted in favor of animals a few times. But just what is an "animal person"? One who turns a blind eye towards human suffering and follows leaders who champion animal causes while still supporting policies that result in the machinegunning of children and unarmed citizens in Central America? To me, "animal people" represent a syndrome that, somewhat understandably, arises out of a deep alienation felt by many champions of animal causes. They feel alienated from a society they see as a collective "villain" in the exploitation of animals. Just as many blacks, in the course of their struggles, have viewed even wellintentioned whites as the enemy; and just as many feminists have viewed all men as evil; many animal advocates see all of humanity as the enemy. It could be called the "hate-the-

oppressor syndrome." And although it's perfectly understandable, it must also be resisted. Why? Because it smacks of selfrightiousness and it gives the animal rights movement a sectarian image. This can only alienate many potential supporters and activists. An image of caring narrowly and exclusively for animals destroys the prospects for seeking supporters and activists where the future of this movement lies---the public at large. For the animal cause is indissolubly tied to other contemporary struggles for justice and sanity in the conduct of human affairs.

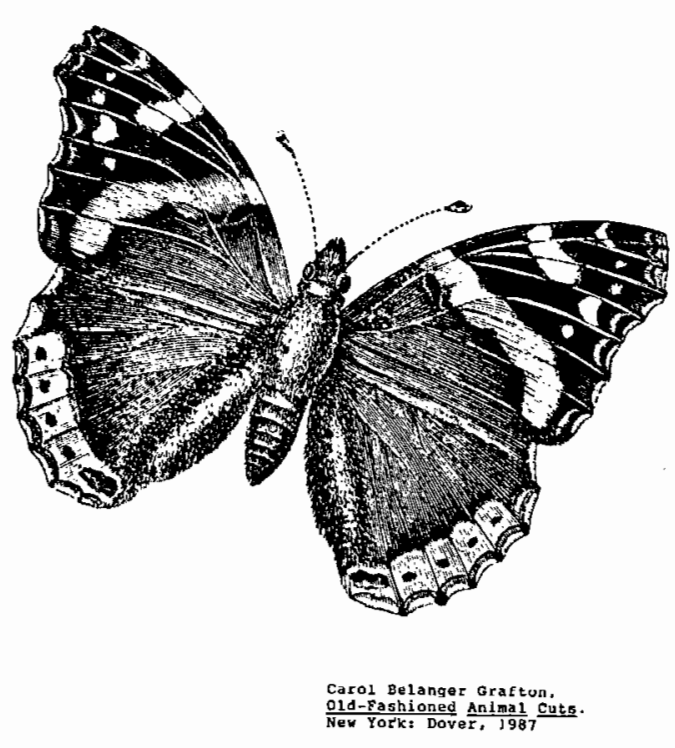

I believe that, instead of thinking and living like a clique of "animal people" (think for a moment how silly it is to hear some people describe themselves as "people people" in defense of their uncaring attitudes about animals), we need to make special efforts to exhude an overall caring attitude for all living beings, and we need to be knowledgeable about world issues other than just our "specialty."

We need to think of animals (and the animal rights movement) as, say, part of the "rainbow" that Jesse Jackson uses to describe the many divisions of life that deserve liberation. It is this perspective (no, not a dilution of efforts!) that will finally command respect for animal rights interests. On the surface, at least, the defense of animals seems to know no class distinction. This has allowed our movement to draw on a broad spectrum of publics. As it grows, however, and reaches deeper into the underlying causes of human and animal exploitation, the choices become clear. Our lot has to be with those who wish to change the world fundamentally, for nothing short of this will represent salvation to the billions of victims who toil and perish today under the current status quo. 
was said, by a Professor of Psychology on the committee, was "Aren't these meetings supposed to be closed?" Within a year new procedures were established for this committee which, taking advantage of a loophole in our campus constitution, closed all further meetings. The Animal Legal Defense Fund is presently preparing a suit against the California State University system to have meetings of its campus animal care committees conform to the provisions of the California state Open Meeting Act. I think that nothing but good can come of having meetings of careless, do-nothing cormittees, like the one at $\mathrm{Cal}$ state Hayward, opened to the public.

Similarly, at the University of California, Berkeley, the campus veterinarian and the chair of the Committee for the Protection of Animal Subjects have tried to tell the community representative from a local humane society that she could not vote against a protocol because she thought the research was worthless. They have even tried to edit her minority reports, and she has had to seek relief from this intimidation by appealing to a UCB Vice Chancellor. (This community representative has had to conclude that her further service on this committee would accomplish nothing, and she has resigned.) Suit is currently also being brought against the University of California system to open the meetings of its campus animal care committees. Again, I can see nothing but good coming from opening arrogant, unrepresentative committees, such as that at Berkeley, to public scrutiny.

For the past two years, I have served as a community member of the Animal Welfare and Research Committee at the Lawrence Berkeley Iaboratory, another part of the University of California. I was invited to serve on this committee because I am supposed to be something of an expert on animal ethics issues and to be active and respected in the animal welfare community. But even though I was thus solicited to be on the cormittee, the resentment at my being there and at my questioning the research protocols was palpable for my first year on the job. The other members of the committee seemed to feel professionally obligated to maintain that everything in the protocols was fine. Fortunately, this defensiveness has pretty much disappeared. Although the others on the comittee still seldom agree with me entirely, we now have frank, critical discussions of protocols, many of which we have returned for significant amendment. We have even voted down a protocol--a virtually unheard-of thing for an animal care committee to do. Opening the meetings of a progressive, conscientious comnittee like this one to the public might, I am afraid, lead to a renewed defensiveness on the part of some comittee members, which would have to be overcome once rgain.

So, as is usual, there are both pros and cons to open meetings. However, my experience leads me to believe that the pros definitely outweigh the cons. Similarly, I view talk of the need to maintain confidentiality for one's ideas as a smokescreen. In my two years at the Lawrence Lab, where there is no tenure, only one researcher has requested confidentiality for her protocol--and everyone on the comittee found that a bit of a joke. Animal care committees do not need to know the creative ideas that win grants and prizes in order to do their job of evaluating humane care and use. Similarly, claims like that by the Chair of the Univerity of Florida ACU committee, that animal activists will distort information from comittee meetings into sensationalist stories, are also smokescreens. If animal activists do that, research institutions can easily discredit them by pointing out the distortions. Actually, the information about research at Florida that has been released accurately pointed out that there were some very shoddy projects proposed there and that the campus animal care committee was not doing a very responsible job. All of us who care about the welfare of research animals should be grateful that Florida is the Sunshine state. And while there may be some growing pains that will accompany the process, we and the animals will be well-served by the spread of that sunshine.

Sincerely,

Steve F. Sapontzis

Professor of Philosophy

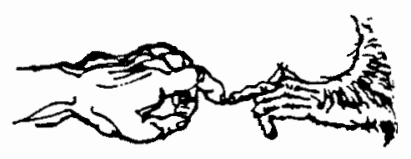

